\title{
STRATEGI PEMETAAN KAWASAN DALAM MENENTUKAN LOKASI YANG TEPAT UNTUK AGROWISATA BUAH DI KABUPATEN SUMENEP
}

\author{
Rusnani, SE., MM ${ }^{1}$ \\ Ribut Santosa, SP., MP ${ }^{2}$ \\ Cholilul Chayati, ST., MT $^{3}$ \\ ${ }^{1}$ Dosen Program Studi Manajemen, Universitas Wiraraja \\ rusnani08@gmail.com \\ ${ }^{2}$ Dosen Program Studi Agribisnis, Universitas Wiraraja \\ ribut.santosa@gmail.com \\ ${ }^{3}$ Dosen Program Studi Teknik Sipil, Universitas Wiraraja \\ cholilul.unija@gmail.com
}

\begin{abstract}
ABTRACT
The natural beauty of Sumenep city is a potential that can be developed into natural and agricultural tourism. Besides the beauty of nature there is also the potential of superior fruits of various kinds and abundant but not yet maximally empowered. The purpose of this research is to know the map of potential areas and the right location for fruit agro-tourism in Sumenep regency. The method used is quantitative method which is the process of exploring the existing potential and understanding the behavior of individuals and groups through samples used with purposive sampling technique, location analysis using Location Quotietient $(L Q)$ motion with primary and secondary data Expected expected output location Right for Fruit Agrowisata Conclusion, the potential location for agro tourism is Batuuan Village Batuan Subdistrict, commodity of plants that have the potential to be developed are dragon fruit, serikaya, watermelon, melon, orange, guava, guava and jackfruit.An appropriate development model is agro tourism Community-based.
\end{abstract}

Keywords : Potential Mapping, Fruit Agro tourism.

\section{PENDAHULUAN}

Sumenep adalah kota yang memiliki wilayah daratan dan kepulauan dimana di setiap daerah baik di daratan maupun kepulauan mempunyai daya tarik sendiri karena di setiap daerah mempunyai potensi yang berbeda-beda. Dengan keindahan alam yang dimiliki kota Sumenep merupakan potensi yang dapat dikembangkan menjadi wisata alam dan pertanian. Disamping keindahan alam ada juga potensi buahbuahan unggulan yang bermacammacam dan berlimpah tetapi belum diberdayakan secara maksimal. Hal ini perlu dikembangkan wisata alam yang dipadukan dengan potensi buah-buahan dalam bentuk agrowisata bua sehingga dapat menjadi daya tarik wisatawan lokal maupun dari luar sehingga dapat meningkatkan pendapatan masyarakat di daerah. Dalam upaya pengembangan agrowisata buah maka perlu dilakukan pemetaan kawasan di daerah-daerah yang mempunyai potensi yang cocok untuk agrowisata buah di Kabupaten Sumenep. 
METODE PENELITIAN

Dalam penelitian ini menggunakan metode penelitian kualitatif yaitu penelitian yang merupakan proses eksplorasi dan memahami makna perilaku individu dan kelompok, menggambarkan masalah sosial atau masalah kemanusiaan (Creswell :2012)

Menurut Basrowi dan Suwandi (2008:11) Suatu prosedur penelitian yang menghasilkan data deskriptif dapat berupa kata-kata yang tertulis atau lisan berasal dari orang-orang atau perilaku yang diamati.

Sumber data dalam penelitian ini adalah data primer dan data sekunder, data primer adalah data yang diperoleh secara langsung di lapangan baik dari tokoh masyarakat,maupun dari penduduk di kabupaten Sumenep. Data sekunder yaitu data yang diperoleh dari dukumen atau instansi terkait berupa buku, jurnal, laporan dan lainnya yang mendukung validitas data primer dalam penelitian ini.

Teknik pengumpulan data melalui wawancara secara langsung kepada nara sumber yaitu tokoh masyarakat, aparat pemerintah, penduduk. Observasi ke lapangan secara langsung dan studi pustaka.

Populasi dalam penelitian ini adalah masyarakat di Kabupaten Sumenep dalam penentuan sampelnya menggunakan teknik purposive sampling yaitu penentuan sampel sesuai dengan kebutuhan panelitian, dalam hal ini tokoh masyarakat dan aparat terkait yang dianggap cukup memahami permasalahan yang ada serta cukup mewakili masyarakat.

\section{Teknik Analisis Data}

Teknik analisa data dilakukan sejak sebelum dilapangan dan analisis pada saat dilapangan yang berlangsung secara intensif dan berlangsung secara terus menerus sampai selesai melalui pengumpulan data, terus reduksi data, penyajian data, dan kesimpulan (Miles dan Huberman 1992)

1. Analisis Lokasi

Dalam menentukan lokasi yang mempunyai potensi pengembangan agrowisata buah dengan menggunakan metode Location Quotient (LQ) tanaman buahbuahan melalui data sekunder dan data primer melalui survey lokasi.dengan rumus sebagai berikut: 


$$
\begin{aligned}
\boldsymbol{L} \boldsymbol{Q}_{\boldsymbol{i}}= & \frac{\boldsymbol{X}_{\boldsymbol{i}}^{r} / \boldsymbol{X}^{r}}{\boldsymbol{X}_{\boldsymbol{i}}^{n} / \boldsymbol{X}^{n}}: \\
& \text { dimana } \mathrm{X}=\text { output (PDRB) } \\
& \mathrm{i}=\text { komoditas } \\
\mathrm{r} & =\text { kecamatan } \\
\mathrm{n} & =\text { kabupaten }
\end{aligned}
$$

Apabila LQ $>1 \rightarrow$ merupakan sektor basis

LQ $<1 \rightarrow$ belum mencukupi kebutuhan konsumsi di daerah setempat

LQ $=1 \rightarrow$ hanya cukup untuk kebutuhan daerah setempat

2. Analisis Potensi

Untuk mengetahui potensi dari buah-buahan maka dapat kita lihat melalui analisis pasar, dukungan sumberdaya yang meliputi sumberdaya alam, sumberdaya lahan, sumberdaya manusia, air, dan lain-lain yang cukup memadai baik dalam jumlah maupun kualitas.

3. Analisa Model Pengembangan

Untuk menemukan sebuah maksud dari suatu tema maka kita perlu pemahaman dari suatu kelompok hal ini dilakukan melalui teknik analisa data Fokus Gruop discussion (FGD) yaitu pengumpulan data yang dilakukan dalam penelitian kualitatif dengan tujuan menemukan maksud sebuah tema untuk mengungkap makna an sebuah kelompok melalui hasil diskusi yang terpusat pada suatu permasalahan.

\section{GAMBARAN UMUM OBYEK PENELITIAN}

Kabupaten Sumenep

merupakan salah satu kota yang berada di wilayah paling ujung timur pulau Madura yang mempunyai 126 pulau dimana pulau ini ada yang berpenghuni sebanyak 48 pulau dan yang tidak berpenghuni sebanyak 78 pulau dan sebagian besar wilayahnya adalah daerah kering dan pegunungan. Letak geografisnya berada $113^{\circ} 32^{\prime} 54^{\prime \prime}$ $116^{\circ} 16^{\prime} 48^{\prime \prime}$ Bujur timur dan $4^{\circ} 55-$ $7^{\circ} 24$ Lintang selatan dengan

- Sebelah Utara Laut Jawa

- Sebelah Selatan : Selat Madura dan laut Bali

- Sebelah Timur : Laut Jawa dan laut Flores

- Sebelah Barat : Kabupaten Pamekasan

\section{Wilayah Geografis}

Wilayah Geografis Kabupaten Sumenep dibagi dua bagian yaitu wilayah daratan dan kepulauan. Sumenep mempunyai 27 kecamatan yang terdiri dari 9 kecamatan berada di kepulauan sedangkan wilayah daratan terdiri dari 18 kecamatan dengan 328 desa dan 4 kelurahan. 


\section{Kondisi Demografi}

Kabupaten Sumenep pada tahun 2013 mempunyai penduduk 1.061.211 jiwa. Tingkat pertumbuhan penduduk dari 2012-2013 mengalami kenaikan sebesar $0,71 \%$ dengan luas wilayah sekitar 2.093,47 km persegi. Setiap kilometer persegi ditempati penduduk sebanyak 507 bjiwa, kepadatan penduduk tertinggi ditempati kecamatan kota dan kecamatan Kalianget. Jumlah penduduk perempuan lebih banyak dibandingkan penduduk laki-laki dengan ratio jenis kelamin 90,69 artinya 91 orang laki-laki : 100 orang perempuan.

Tabel 1.

Pembagian Wilayah Kabupaten Sumenep

\begin{tabular}{|l|l|c|c|}
\hline No. & \multicolumn{1}{|c|}{ Wilayah } & Luas $(\mathrm{km} 2)$ & Persentase \\
\hline 1 & Daratan & $1.147,24$ & 57,40 \\
\hline 2 & Kepulauan & 851,30 & 42,30 \\
\hline & Jumlah & $1.998,54$ & 100 \\
\hline
\end{tabular}

Sumber : Badan Perencanaan Daerah Kabupaten Sumenep

Tabel 2.

Jumlah Penduduk Kabupaten Sumenep

\begin{tabular}{|l|l|c|c|}
\hline No. & Jenis Kelamin & Jumlah (jiwa) & Persentase(\%) \\
\hline 1 & Laki-laki & 504.712 & 47,56 \\
\hline 2 & Perempuan & 556.499 & 52,44 \\
\hline & & 1.061 .211 & 100 \\
\hline
\end{tabular}

Sumber : Dinas Tenaga Kerja \& Transmigrasi Kabupaten Sumenep

Tabel 3.

Jumlah Angkatan Kerja, Kesempatan Kerja,Pencari Kerja, Pengangguran Kabupaten Sumenep

\begin{tabular}{|c|c|c|c|}
\hline Angkatan Kerja. & Kesempatan Kerja & Pencari Kerja & Pengngguran \\
\hline 651.220 & 631.534 & 19.456 & 19.532 \\
\hline
\end{tabular}

Sumber : Dinas Tenaga Kerja \& Transmigrasi Kabupaten Sumenep

Tabel 4.

Kesempatan Kerja menurut Lapangan Usaha di Kabupaten Sumenep

\begin{tabular}{|l|l|c|c|}
\hline No. & Jenis Usaha & Jumlah (jiwa) & Persentase(\%) \\
\hline 1 & Pertanian & 283.559 & 44,90 \\
\hline 2 & Pertambangan & 5.684 & 0,90 \\
\hline 4 & Industri pengolahan & 51.154 & 8,10 \\
\hline 5 & Listrik, gas, air & 6.947 & 1,10 \\
\hline 6 & Bangunan & 30.314 & 4,80 \\
\hline 7 & Perdagangan & 107.992 & 17,10 \\
\hline 8 & Angkutan & 45.470 & 7,20 \\
\hline 9 & Perbankan & 13.894 & 2.20 \\
\hline 10 & Jasa & 86.520 & 13,70 \\
\hline & Jumlah & 631.543 & 100 \\
\hline
\end{tabular}

Sumber : Dinas Tenaga Kerja \& Transmigrasi Kabupaten Sumenep 
Dilihat dari tabel 3 diatas jumlah angkatan kerja lebih besar dari jumlah kesempatan kerja sehingga terdapat pengangguran sebanyak 19.532 orang.

Dari tabel 4 kesempatan kerja berdasarkan lapangan usaha masih banyak peluang yang dapat diisi oleh 19.532 orang yang masih menganggur tentunya yang sesuai dengan kemampuannya.Dari data diatas yanga paling banyak membutuhkan tenaga kerja adalah di sektor pertanian, perdagangan dan jasa.

Pertumbuhan ekonomi Kabupaten Sumenep mengalami peningkatan dari tahun 2011 sampai 2014, tingkat pertumbuhan yang paling tinggi pada sektor keuangan, persewaan dan jasa perusahaan hal ini membantu peningkatan PDRB Kabupaten Sumenep menjadi Rp 6,44 Juta dapat dilihat pada tabel berikut,

Tabel 4.

Pertumbuhan Ekonomi Menurut Lapangan Usaha

$2011-2013$

(Juta Rp)

\begin{tabular}{|c|l|c|c|c|}
\hline No & \multicolumn{1}{|c|}{ Lapangan Usaha } & Th 2011 & Th 2013 & Th 2014 \\
\hline 1. & Pertanian & 3,29 & 3,56 & 3,50 \\
\hline 2. & Pertambangan \& Penggalian & 5.15 & 5,22 & 9,68 \\
\hline 3. & Industri Pengolahan & 6,94 & 7,75 & 11,91 \\
\hline 4. & Listrik, Gas, Air & 6,01 & 6,39 & 5,61 \\
\hline 5. & Bangunan & 7,88 & 8,06 & 9,19 \\
\hline 6. & Perdagangan, Hotel, Restoran & 12,99 & 11,42 & 9,61 \\
\hline 7. & Pengangkutan dan Komunikasi & 7,99 & 8.48 & 9,44 \\
\hline 8. & $\begin{array}{l}\text { Keuangan, Persewaan, Jasa } \\
\text { Perusahaan }\end{array}$ & 8,41 & 8,87 & 12,48 \\
\hline 9. & Jasa-jasa & 5.33 & 6,69 & 5,90 \\
\hline & PDRB & 6,24 & 6,33 & 6,44 \\
\hline
\end{tabular}

Sumber : BPS Sumenep dalam angka 2014

Tabel 5.

Luas Areal Menurut Penggunaannya di Kabupaten Sumenep

\begin{tabular}{|c|l|c|c|}
\hline & \multicolumn{1}{|c|}{ Jumlah Lahan Persawahan } & & Tahun 2014 \\
\hline 1 & Sawah irigasi & $\mathrm{Ha}$ & 25.157 \\
\hline 2 & Sawah tadah hujan & $\mathrm{Ha}$ & 8.854 \\
\hline 3 & Sawah pasang surut & $\mathrm{Ha}$ & 16.303 \\
\hline & Luas penggunaan Lahan bukan Sawah & $\mathrm{Ha}$ & 146.604 \\
\hline 1 & Kolam/empang/tambak/danau/telaga & $\mathrm{Ha}$ & 12.753 \\
\hline 2 & Ladang/tegalan/kebun/padang rumput & $\mathrm{Ha}$ & 121.943 \\
\hline 3 & Perkebunan & $\mathrm{Ha}$ & 2.072 \\
\hline 4 & Hutan & $\mathrm{Ha}$ & 4.695 \\
\hline 5 & Industri/pemukiman & $\mathrm{Ha}$ & 37.585 \\
\hline 6 & Non sawah belum diusahakan & $\mathrm{Ha}$ & 5.141 \\
\hline 7 & Lainnya & $\mathrm{Ha}$ & 12.753 \\
\hline & & & \\
\hline
\end{tabular}

Sumber : Dinas Pertanian Tanaman Pangan Kabupaten Sumenep data diolah 
Dari tabel diatas menunjukkan bahwa luas areal yang paling banyak digunakan adalah lahan bukan sawah yaitu tegalan/kebun seluas 121.943 ha, ini menunjukkan bahwa hasil pertanian yang paling banyak dan berpengaruh di Kabupaten Sumenep adalah hasil pertanian dari tanaman tegalan atau tanah kering atau kebun.

Sehubungan dengan penggunaan lahan yang paling banyak adalah lahan tegal maka Komuditas tanaman tegal dapat menentukan tinggi rendahnya pendapatan petani, jadi semakin tinggi produktifitas tanaman tegal maka penghasilan masyarakat petani akan semakin tinggi begitu juga sebaliknya.

\section{PEMBAHASAN}

Berdasarkan hasil analisis Lokation Quotient (LQ) tanaman buah buahan di setiap kecamatan di Kabupaten Sumenep sebagai berikut :

\section{Analisa Lokasi}

Pada tujuan penelitian pertama yakni untuk menentukan pewilayahan basis buah-buahan, penelitian ini menggunakan metode Location Quotient $(L Q)$ yang merupakan metode ekonomi basis yang sering digunakan dan relatif sederhana. Dengan menggunakan penghitungan nilai LQ pada 27 kecamatan yang ada di Kabupaten Sumenep maka nilai LQ tertinggi berada pada Kecamatan Pragaan dengan skor nilai 15,842 sedangkan nilai LQ terendah berada pada Kecamatan Saronggi dengan skor nilai 0,160 (lihat Tabel 1). Berdasarkan nilai LQ tertinggi dan terendah tersebut maka ditetapkan bahwa Kecamatan Pragaan merupakan kecamatan wilayah basis buah naga di Kabupaten Sumenep sedangkan Kecamatan Saronggi ditetapkan sebagai wilayah kecamatan non basis buah naga yang diteliti.

Daerah yang mempunyai nilai LQ luas panen buah naga yang bernilai 0 (nol) adalah wilayah Kecamatan Giligenting, Talango, Kalianget, Sumenep, Ganding, Pasongsongan, Ambunten, Dasuk, Batu Putih, Gapura, Batang-batang, Dungkek, Nonggunung, Raas, Sapekan, Arjasa, Kangayan dan Masalembu menunjukkan bahwa 19 wilayah tersebut sama sekali tidak memiliki share luas panen buah nagai terhadap luas panen tanaman buahbuahan di kecamatannya. 
Tabel 6.

Nilai LQ Luas Panen Buah-Buahan Masing-masing Kecamatan di Kabupaten Sumenep

\begin{tabular}{|l|c|c|c|c|c|c|c|c|}
\hline \multicolumn{1}{|c|}{ Kecamatan } & $\begin{array}{c}\text { Buah } \\
\text { Naga }\end{array}$ & Srikaya & Melon & Nangka & $\begin{array}{c}\text { Jambu } \\
\text { Air }\end{array}$ & Semangka & $\begin{array}{c}\text { Jambu } \\
\text { Biji }\end{array}$ & Jeruk \\
\hline Pragaan & 15,842 & 0,451 & 1,948 & 2,060 & 0,216 & 0,434 & 0,203 & 0,000 \\
\hline Bluto & 1,003 & 0,000 & 2,048 & 2,375 & 0,477 & 0,959 & 0,449 & 0,000 \\
\hline Saronggi & 0,146 & 7,203 & 0,217 & 0,515 & 0,111 & 0,224 & 0,105 & 0,162 \\
\hline Giligenting & 0,000 & 0,000 & 0,000 & 2,179 & 0,664 & 1,335 & 0,625 & 0,000 \\
\hline Talango & 0,000 & 1,214 & 4,027 & 2,437 & 0,193 & 0,387 & 0,181 & 0,300 \\
\hline Kalianget & 0,000 & 0,164 & 0,000 & 0,476 & 1,116 & 2,244 & 1,050 & 0,812 \\
\hline Sumenep & 0,281 & 0,039 & 0,412 & 0,113 & 2,066 & 0,817 & 1,944 & 0,000 \\
\hline Batuan & 0,433 & 0,000 & 8,881 & 0,139 & 1,165 & 0,681 & 1,096 & 0,946 \\
\hline Lenteng & 0,267 & 0,294 & 0,195 & 3,203 & 0,292 & 0,587 & 0,275 & 0,509 \\
\hline Ganding & 0,000 & 0,306 & 0,813 & 1,422 & 0,799 & 1,606 & 0,752 & 0,000 \\
\hline Guluk-Guluk & 0,929 & 0,000 & 4,444 & 0,333 & 0,893 & 1,796 & 0,841 & 1,949 \\
\hline Pasongsongan & 0,316 & 3,440 & 0,578 & 2,549 & 0,000 & 0,124 & 0,000 & 0,000 \\
\hline Ambunten & 0,772 & 0,000 & 0,960 & 0,669 & 1,386 & 1,394 & 1,305 & 0,000 \\
\hline Rubaru & 0,305 & 0,182 & 0,186 & 0,047 & 0,278 & 0,279 & 3,990 & 1,663 \\
\hline Dasuk & 0,000 & 0,016 & 0,210 & 0,964 & 1,273 & 1,009 & 1,198 & 4,146 \\
\hline Manding & 2,718 & 0,110 & 1,462 & 0,373 & 1,124 & 1,130 & 1,058 & 7,085 \\
\hline Batuputih & 0,454 & 0,063 & 0,830 & 0,847 & 1,240 & 1,247 & 1,167 & 2,165 \\
\hline Gapura & 0,125 & 0,017 & 0,638 & 0,125 & 4,400 & 0,450 & 0,055 & 0,000 \\
\hline Batang-Batang & 1,111 & 0,153 & 2,033 & 0,519 & 1,302 & 1,309 & 1,225 & 0,758 \\
\hline Dungkek & 0,147 & 0,020 & 0,268 & 0,186 & 0,206 & 4,350 & 0,345 & 0,100 \\
\hline Nonggunong & 1,449 & 0,200 & 0,000 & 0,676 & 1,359 & 1,366 & 1,279 & 0,988 \\
\hline Gayam & 0,000 & 2,625 & 0,000 & 0,635 & 0,744 & 0,748 & 0,700 & 6,494 \\
\hline Raas & 0,000 & 3,828 & 2,033 & 0,370 & 0,434 & 0,436 & 0,408 & 7,576 \\
\hline Sapeken & 0,000 & 0,551 & 0,000 & 0,622 & 1,354 & 1,361 & 1,275 & 0,909 \\
\hline Arjasa & 0,000 & 0,606 & 1,340 & 0,049 & 1,488 & 1,496 & 1,401 & 0,500 \\
\hline Kangayan & 0,000 & 0,799 & 2,651 & 0,097 & 1,359 & 1,366 & 1,279 & 0,000 \\
\hline Masalembu & 0,000 & 0,000 & 2,139 & 0,546 & 1,279 & 1,286 & 1,376 & 0,797 \\
\hline Ketangan & $N 120$ & 1906 & \\
\hline
\end{tabular}

Keterangan: *Nilai LQ diperoleh berdasarkan luas panen masing-masing komoditas yang dihitung menggunakan data sekunder luas panen dari Badan Pusat Statistik tahun 2015; **: wilayah basis; ***: nilai LQ tertinggi

Untuk mempermudah

penghitungan nilai LQ luas panen naga dapat menggunakan bantuan microsoft excell 2007 agar lebih mudah diperoleh nilai LQ luas buah naga seluruh kecamatan Pragaan di Kabupaten
Sumenep. Berikut ini cara mencari Nilai LQ luas panen buah-buahan jika menggunakan penghitungan secara manual, Kecamatan Pragaan Sumenep sebagai contoh, dengan menggunakan rumus umum LQ yaitu: 


$$
\begin{gathered}
\boldsymbol{L} \boldsymbol{Q}_{i}=\frac{\boldsymbol{X}_{i}^{r} / \boldsymbol{X}^{r}}{\boldsymbol{X}_{\boldsymbol{i}}^{n} / \boldsymbol{X}^{n}}: \\
L Q=\frac{6,39 / 26}{8,66 / 568,74} \\
\mathrm{LQ}=15,824
\end{gathered}
$$

Dimana :

i $\quad=$ Komoditas Buah Naga

$\mathrm{r} \quad=$ Kecamatan Pragaan

$\mathrm{n} \quad=$ Kabupaten Sumenep

$X_{i}^{r} \quad=$ Luas Areal Panen Komoditas Buah Naga di Wilayah Kecamatan Pragaan = 6,39 hektar

$X_{i}^{n} \quad=$ Luas Areal Panen Komoditas Buah Naga di Wilayah Kabupaten Sumenep = 26 hektar;

$\mathrm{X}^{\mathrm{r}}=$ Luas Areal Panen Total Tanaman buah di Wilayah Kecamatan Kota Sumenep $=$ 8,66 hektar;

$\mathrm{X}^{\mathrm{n}} \quad=$ Luas Areal Panen Total Tanaman buah-buahan di Wilayah Kabupaten Sumenep $=568,74$ hektar.

Dengan menggunakan penghitungan manual tersebut maka didapatkan bahwa nilai LQ Kecamatan Pragaan sebesar 15,842. Berdasarkan kriteria penentuan basis komoditas dengan menggunakan LQ yang menyebutkan bahwa apabila suatu wilayah memiliki nilai LQ lebih dari 1 satu (1) maka wilayah tersebut merupakan basis komoditas yang dihitung (Hendayana, 2003). Oleh karena itu, Kecamatan Pragaan merupakan wilayah basis buah naga karena nilai LQ -nya lebih besar dari satu.

\section{Penggunaan penghitungan LQ} pada penelitian ini juga menghitung nilai LQ komoditas lainnya sehingga sehingga dapat mengetahui wilayah basis komoditas tanaman buah yang lainnya yang ada dii Kabupaten
Sumenep. Pada Tabel 6. secara lengkap dapat dilihat hasil penghitungan LQ masing-masing komoditas tanaman buah pada seluruh kecamatan di Kabupaten Sumenep.

Berdasarkan Tabel 6. dapat dilihat bahwa wilayah basis (memiliki nilai LQ lebih dari 1) untuk masingmasing di Kabupaten Sumenep adalah sebagai berikut:

1. Basis Buah Naga

Kecamatan Pragaan, Manding, Batang-batang dan Nonggunong

2. Basis Srikaya

Kecamatan Saraonggi, Talango, Pasongsongan, Gayam dan Raas

3. Basis Melon

Kecamatan Batuan, Pragaan, Bluto, Talango, Guluk-guluk, Manding. Batang-batang, Raas, Arjasa, Kangayan, Masalembu 
4. Basis Nangka

Kecamatan Lenteng, Pragaan,

Bluto, Giligenting, Talango,

Pasongsongan, dan Ganding

5. Basis Jambu Air

Kecamatan Gapura, Batuan,

Kalianget, Sumenep, Batuan,

Ambunten, Dasuk, Manding, Batu

putih, Batang-batang, Nongunong,

dSapeken, Arjasa, Kangayan,

Masalembu

6. Basis Semangka

Kecamatan

Dungkek,

Kalianget,Ganding, Guluk-guluk,

Ambunten, Dasuk Manding, Batu

Putih, Batang-batang, Nunggunong,

Sapeken,

Arjasa,Kangayan,

Masalembu

7. Basis Jambu Biji

Kecamatan Rubaru, Kalianget,

Sumenep, Batuan, Ambunten,

Dasuk, Manding, Batu Putih,

Batang-batang, Nonggunong,

Sapeken, Arjasa, Kangayan,

Masalembu

8. Basis Jeruk

Kecamatan Raas, Gayam,

Batupuutih, Manding, Dasuk,

Rubaru, Guluk-guluk

Dari delapan wilayah basis

komoditas tanaman buah-buahan

tersebut menunjukkan bahwa setiap

komoditas tanaman minimal memiliki empat wilayah basis. Dari setiap komoditas tanaman tersebut hanya ada satu wilayah basis dengan nilai LQ tertinggi. Pada Tabel 6. dapat dilihat bahwa nilai LQ tertinggi untuk komoditas buah naga terdapat di Kecamatan Pragaan $(15,842)$, komoditas Serikaya terletak di Kecamatan Saronggi $(7,203)$, komoditas melon terdapat di Kecamatan Batuan (8.881), Komoditas nangka terdapat di Kecamatan Lenteng (3.203), komoditas jambu air terdapat di Kecamata Sumenep (2.066) komoditas semangka terdapat di Kecamatan Dungkek $(4,350)$, komoditas Jambu biji terdapat di kecamatan Rubaru (3,990), komoditas Jeruk terdapat di Kecamatan Raas $(7,576)$

Untuk menentukan lokasi yang terbaik dalam pengembangan agrowisata buah di Kabupaten Sumenep tidak hanya berdasarkan pada perhitungan daerah basis berdasarkan LQ tetapi dalam penelitian ini peneliti menggunakan beberapa pertimbangan yang lainnya seperi :

1. Sinergi dengan kebijakan pemerintah setempat

2. Sarana dan prasarana pendukung

3. Akses menuju lokasi

Sinergi dengan kebijakan pemerintah Kabupaten Sumenep merupakan prioritas bagi peneliti karena harus menyesuaikan dengan tatakota Kabupaten Sumenep oleh karena itu peneliti melakukan Focus Group 
Discussion (FGD) dengan melakukan pertemuan dengan tokoh kunci misalnya Dinas pertanian, Badan Perencanaan dan Pembangunan Daerah, Dinas Pariwisata, ahli planologi, Penyuluh Pertanian Lapangan, Kepala Desa, Ketua Gabungan Kelompok Tani

Sarana dan prasarana yang tersedia di kecamatan yang mempunyai basis buah paling tinggi perlu diperhatikan hal ini merupakan pertimbangan dalam memilih lokasi agrowisata buah. Melihat dari has il survey tim ternyata Kecamatan Batuan memiliki sarana dan prasarana yang lebih menunjang diantaranya:

- Struktur tanahnya bisa ditanami berbagai macam tanaman

- Lokasinya strategis

- $\quad$ Ada sumber air

- Infrastrukturnya bagus

- Transportasi mudah

- Dekat dengan Puskesmas

- Dekat Kantor Kecamatan Batuan

- Dekat Kantor Polisi

- $\quad$ Dekat Islamic center

- Dekat Mesjid

- Dekat Sanggar Kegiatan Belajar (SKB)

Kemudahan Akses
kemudahan jalan menuju lokasi
pengembangan agrowisata
Kecamatan Batuan mempunyai akses
yang paling baik dan lebih mudah
dijangkau dibandingkan kecamatan

lainnya karena disamping infrastruktur yang lebar dan baik sarana transportasi mudah karena dilaluli kendaraan dari Kota menuju Kecamatan Lenteng sarana penunjang lainnya ada seperti dekat dengan lokasi wisata yang lain seperti Taman Sumekar Indah, Asta Tinggi, Musium, Kraton, Water Park Sumekar, Bukit Tinggi sehingga hal ini menjadi pertimbangan positip untuk memilih kecamatan Batuan sebagai lokasi Agrowisata Buah.

\section{Analisa Potensi}

Desa Batuan Kecamatan Batuan mempunyai lahan dengan agroklimat yang sesuai dengan tanaman buahbuahan disamping itu desa Batuan mempunyai panorama alam yang bagus dan strategis serta mudah dijangkau dari lokasi wisata yang lainnya. Disamping flora dan faon, pegunungan dan persawahan yang luas membuat pemandangan yang indah, dari segi pengairan terdapat sumber air yang cukup besar karena merupakan sumber dari peninggalan kerajaan sehingga untuk pengairan tidak akan kekurangan,

Dengan Prasarana dan infra struktur yang memadai seperti jalan dan angkutan cukup banyak dan jarak dari kota cukup dekat, sarana peribadatan, sarana puskesmas, listrik,air, akses ke tempat wisata yang lain sangat dekat sehingga akan memudahkan wisatawan 
untuk berkunjung hal ini merupakan kelebihan yang dimiliki Desa Batuan Kecamatan Batuan.

\section{Kesimpulan}

Berdasarkan hasil penelitian yang telah dilakukan maka dapat diambil kesimpulan sebagai berikut:

1. Agrowisata Buah berpotensi dikembangkan di desa Batuan, kecamatan Batuan Kabupaten Sumenep.

2. Komoditas tanaman buah yang berpotensi dikembangkan adalah Buah naga, semangka, melon, srikaya, jeruk, Jambu air, Jambu biji, nangka

3. Model pengembangan agrowisata buah yang tepat dikembangkan dengan model agrowisata buah berbasis masyarakat agar dapat menyerap tenaga yang masih menganggur.

\section{Saran}

Perlu dilakukan penelitian lebih lanjut untuk menganalisis persepsi masyarakat dan studi kelayakan terhadap pengembangan agrowisata buah di Kabupaten Sumenep.

\section{DAFTAR PUSTAKA}

Anwar, Sanusi, 2011. Metodologi Penelitian Bisnis, Salemba Empat , Jakarta

Departemen Kebudayaan dan Pariwisata, 2009. Prinsip dan Kreteria Ekowisata

Gelgel, I Putu, 2009. Industri Pariwisata Indonesia Dalam Globalisasi
Perdagangan Jasa. PT.Refika Aditama Bandung.

Kusmayadi dan Enda Sugiarto. 2000. Metodologi Penelitian dalam Bidang Kepariwisataan. Jakarta: PT. Gramedia Pustaka Utama

Moleong, Lexy J. 1994. Metodologi Penelitian Kualitatif. Bandung PT Remaja Rosdakarya

Miles, Matthew B dan A Michael Huberman 1992. Analisis Data kualitatif Jakarta : Penerbit Universitas Indonesia

PS, 2007. Agribisnis Tanaman Buah, Perbar Swadaya, Jakarta

Sedarmayanti,2014. Membangun dan Mengembngkan Kebudayaan dan Industri Pariwisata. PT Refika Aditama Bandung.

Singarimbun , Masri dan Sofyan Effendi. 1989. Metode Penelitian Survei. Jakarta PT Pustaka LP3ES Indonesia

Sutjipto, I Nyoman, 2001, Agrowisata, Magister Manajemen Agribisnis ; Universitas Udayana (Diktat)

Sugiyono, 2010. Metodologi Kuantitatif, Kualitatif, dan R \& D, Bandung Alfabeta

Undang - undang Republik Indonesia Nomor 10 Tahun 2009 Tentang Kepariwisataan

Undang - undang Nomor 25 Tahun 2004 Tentang Sistem Perencannaan Pembangunan Nasional

Yoeti, Oka A, 2005. Perencanaan Strategis Pemasaran Daerah Tujuan Wisata. PT Pradnya Paramita Jakarta.

Yoeti, Oka A, 1996. Pemasaran Pariwisata. Angkasa Bandung 